\title{
Evaluation of Influencing Factors and commonly Involving Side in Maxillofacial Injuries in Road Traffic Accidents by Motorized Two Wheelers: A Cross-sectional Study
}

\author{
${ }^{1} \mathrm{~S}$ Mohanavalli, ${ }^{2}$ Meera Thinakaran, ${ }^{3} \mathrm{G}$ Sree V Bala
}

\begin{abstract}
Introduction: Trauma remains to be a leading cause of maxillofacial injury globally. Motorized two wheelers (MTWs) are the main cause of $(73 \%)$ maxillofacial injuries in the road traffic accidents; in several studies, the right side of maxillofacial injuries was reported as the common side of injury than left side. In our previous study, the percentage of the right side injuries was higher than the left side.
\end{abstract}

Aim: The aim of this study is to evaluate the influencing factors of the maxillofacial injury by MTWs and to find the association between the side maxillofacial injuries and the handedness of drivers.

Materials and methods: Clusters sampling method was used; 20 clusters were selected in Chennai. Motorized twowheeler drivers were selected. Data collected by prepared questionnaires' were statistically analyzed. Data included the demographic details, type of vehicle, engine capacity, average driving speed, years of driving, regular usage of the helmet, type, mode and frequency of accident, management, influence of alcohol, and use of the helmet at the time of injury. The side of the facial injury and handedness of drivers were recorded.

Results: From the total of 721 participants, $75.7 \%$ were males, $24.3 \%$ were females; $46.74 \%$ were in the age of 18 to 25 ; mean age is 29.45 . Bikes were $55.9 \%$, scooter $38.2 \%$, moped $8.3 \%$; $59.9 \%$ are geared; $50.5 \%$ were 80 to $100 \mathrm{cc}$ vehicles types and $37 \%$ were 110 to 150 cc types; $62 \%$ of male's average speed is 80 $\mathrm{km} / \mathrm{hour} ; 53 \%$ of female's average speed is less than $40 \mathrm{~km} / \mathrm{hour}$. Only $18.06 \%$ had used at the time of injury. $39.4 \%$ of females had accidents, males had $59.3 \%(p<0.0001)$. Two-wheeler vs two-wheeler accidents were $24.8 \%$; two-wheeler vs four wheeler were $19 \%$; by pedestrians crossing $18.7 \%$; by animal crossing was $16.5 \%$; skid two wheeler $20 \%$. A total of $30.02 \%$ were under the influence of alcohol. Right-side injuries were $44.5 \%$; left side $25.9 \%$ ( $p<0.0001$ ), while $96.9 \%$ were right-handers.

Conclusion: Right-side injuries were common in MTW skid and fall. Speed, type of vehicle, handedness, influence of alcohol, use of helmet, mode of injury, all are the determining factors

\footnotetext{
${ }^{1}$ Professor and Head, ${ }^{2}$ Principal and Head, ${ }^{3}$ Assistant Professor

${ }^{1,3}$ Department of Dentistry, ESIC Medical College and Postgraduate Institute of Medical Sciences and Research Chennai, Tamil Nadu, India

${ }^{2}$ Department of Oral and Maxillofacial Surgery, Karpaga Vinayaga Institute of Dental Sciences, Chennai, Tamil Nadu, India

Corresponding Author: S Mohanavalli, Professor and Head Department of Dentistry, ESIC Medical College and Postgraduate Institute of Medical Sciences and Research, Chennai, Tamil Nadu, India, Phone: +914424748959; +919444106023, e-mail: mona13omfs@gmail.com
}

for pattern and severity of injury. Helmet usage would definitely minimize the head injury to some extent.

Keywords: Accident, Facial, Injury, Maxillary, Skid, Two wheeler.

How to cite this article: Mohanavalli S, Thinakaran M, Bala GSV. Evaluation of Influencing Factors and commonly Involving Side in Maxillofacial Injuries in Road Traffic Accidents by Motorized Two Wheelers: A Cross-sectional Study. World J Dent 2017;8(1):49-54.

\section{Source of support: Nil}

Conflict of interest: None

\section{INTRODUCTION}

Trauma remains a leading cause of maxillofacial injury globally. Changing etiology and patterns of maxillofacial injury also have been reported and are certainly influenced by sociogeographic and environmental factors. It is essential to have an in-depth understanding of the etiology and pattern in that particular sociogeographic region before developing any effective preventive measures. Despite improvements in automotive safety, traffic rules, and laws, the Motor Vehicle Collision-related facial injuries continue to be high in developing countries. Nearly 73\% of two wheelers have registered as a proportion of all vehicle registered in Indian cities. ${ }^{1}$ In Chennai, it is the indispensable mode of transport for the young adults because of its convenient and their passion in driving two wheelers. In the road traffic-related accidents, $70 \%$ are by motorized two wheeler (MTW) accidents. ${ }^{2,3}$ The morbidity and mortality of maxillofacial injuries persist high and the disability related to nonfatal injuries also was wide ranging, in spite of the advances in access to trauma care systems and in the management. ${ }^{4-7}$ Some authors have reported that right-side injuries were common than the left side. ${ }^{8-10}$ A retrospective study was conducted in our center about the pattern and etiology of the maxillofacial injuries. The percentage of the right-side injuries was higher than the left side, and was statistically significant. This cross-sectional study was conducted as a continuation of the previous study and to confirm the above findings.

The aim was to evaluate the factors influencing the maxillofacial injury in road traffic-related accidents by MTWs, like vehicle type, engine type, average driving speed, usage, and usefulness of helmet while driving, and 
to study the correlation between the side of maxillofacial injuries and the handedness of drivers.

\section{MATERIALS AND METHODS}

Cluster sampling method was used. Chennai City was selected and the subdivisions/areas of Chennai were considered as clusters and random clusters selected from subdivisions. In the selected cluster, we had organized a spot at each area to distribute the questionnaire to the two-wheeler travelers who randomly reached the spot on the sample collection day. In each cluster, approximately 35 to $40(35 \times 20=700$ to 750$)$ two-wheeler riders were included in the survey. The purpose of the study was explained to all. Whoever willing to participate were included and the informed consent was obtained. Questionnaires' were issued and filled by the participants.

The demographic details, type of vehicle, engine type, average driving speed, years of driving, regular usage of the helmet were collected. History of the accident while driving two wheeler, mode of injury, frequency or number of accident, hospitalized or underwent treatment or surgery for injuries, the side of the facial injury, use of helmet, and the influence of alcohol at the time of injury were recorded. Right- or left-handers were recorded to find out the correlation between the handedness and the side of the facial injury.

\section{RESULTS}

In each cluster, 35 to 40 participants were surveyed, and totally 750 two-wheeler riders were included. All columns completely filled forms (721 samples [750 = 96.1\%]) were taken for data analysis. Data collected were statistically analyzed by using Statistical Package for the Social Sciences (SPSS) software version 16.0 (Table 1).

\section{Gender Distribution}

Male participants were nearly $75.7 \%$ (546), females were $24.3 \%$ (175) in that $46.74 \%$ (337 = 241 males +96 females $)$ were in the age group of 18 to 25 , mean age is 29.45 [standard deviation $=5.57$, minimum and maximum $=18$ to 68 years (Graph 1$)]$.

\section{Vehicle Type}

Out of $(n=721)$ participants, bike users were $55.5 \%$, scooter users $38.2 \%$, and moped 6.3\%. In male (546) participants, the bike users account for $72.3 \%$, scooter $19.3 \%$, and moped $8.4 \%$. Out of 175 female participants, the usage of bike accounts for $4.5 \%$, scooter accounts $96 \%$, and $1.1 \%$ were moped users.

\section{Engine Type}

Out of total of 721, the geared (G) vehicle users were $59.9 \%$ and without geared (NG) vehicles were 39.1\% (294). Males

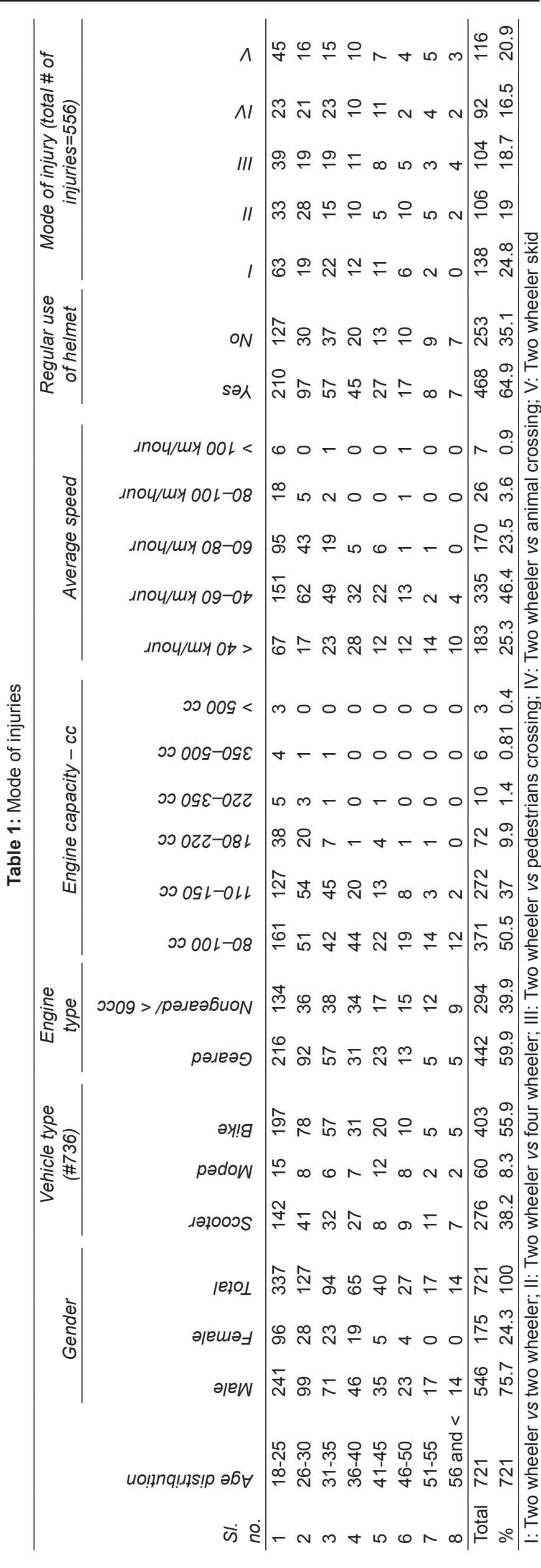




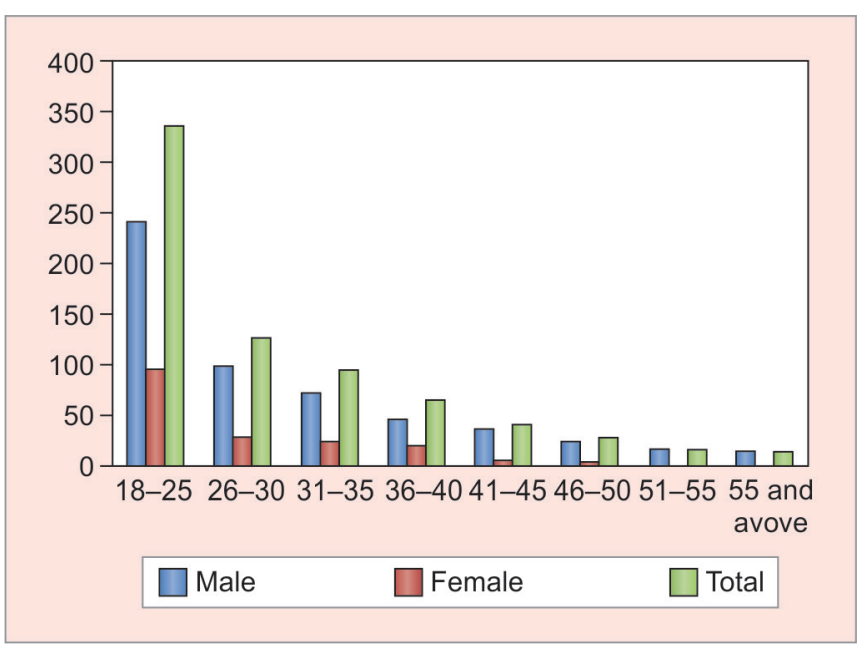

Graph 1: Agewise male and female participants

reported that $74 \%$ are using geared vehicle, while $19.4 \%$ are without gear and $1.6 \%$ are using both geared and NG vehicles. Females are using $18.8 \%$ geared and $91.4 \%$ NG vehicles, $4 \%$ are using both types.

\section{Engine Capacity}

Three Cylinder capacity (cc): Categories: I [80-110 cc] accounts for $50.5 \%$; II [110-150 cc] accounts for 37\%; III [180-220 cc] was nearly 9.9\%; IV [230-350 cc] was $1.4 \%$; V [350-500 cc] was around $0.8 \%(\mathrm{n}=6)$; VI more than [ $500 \mathrm{cc}$ ] was $0.4 \%$ only.

\section{Average Speed of Driving}

This was categorized into five groups: Group I [less than $40 \mathrm{~km} /$ hour] accounts for $25.3 \%$; group II [40-60 km/hour] was about $46.4 \%$; group III [60-80 km/hour] accounts for $23.5 \%$; group IV [ $80-100 \mathrm{~km} /$ hour] was $3.6 \%$; group V [100 km/hour and above] accounts for $0.9 \%$ only. $62 \%$ of males in the age of 18 to $26 \mathrm{had}$ reported that their average speed would be above $80 \mathrm{~km} /$ hour; $39 \%$ had reported above $100 \mathrm{~km} /$ hour speed. Female's (53\%) average driving speed is less than $40 \mathrm{~km} /$ hour; $38 \%$ had reported between 40 and $60 \mathrm{~km} /$ hour. Mean years of driving was 6.6 years (standard deviation $=5.57$ ), with the minimum and maximum as 1 and 30 years.

\section{Regular Usage of Helmet}

Of participants, $64 \%$ reported that they were using regularly; $35.1 \%$ were not using regularly. At the time of injury, only $18.06 \%$ had used the helmet and above $81.9 \%$ were not wearing the helmet.

\section{Injury History and Mode of Injury}

Table 2 shows nearly $54.5 \%$ participants had mild to severe injury and minimum of one time to maximum of four

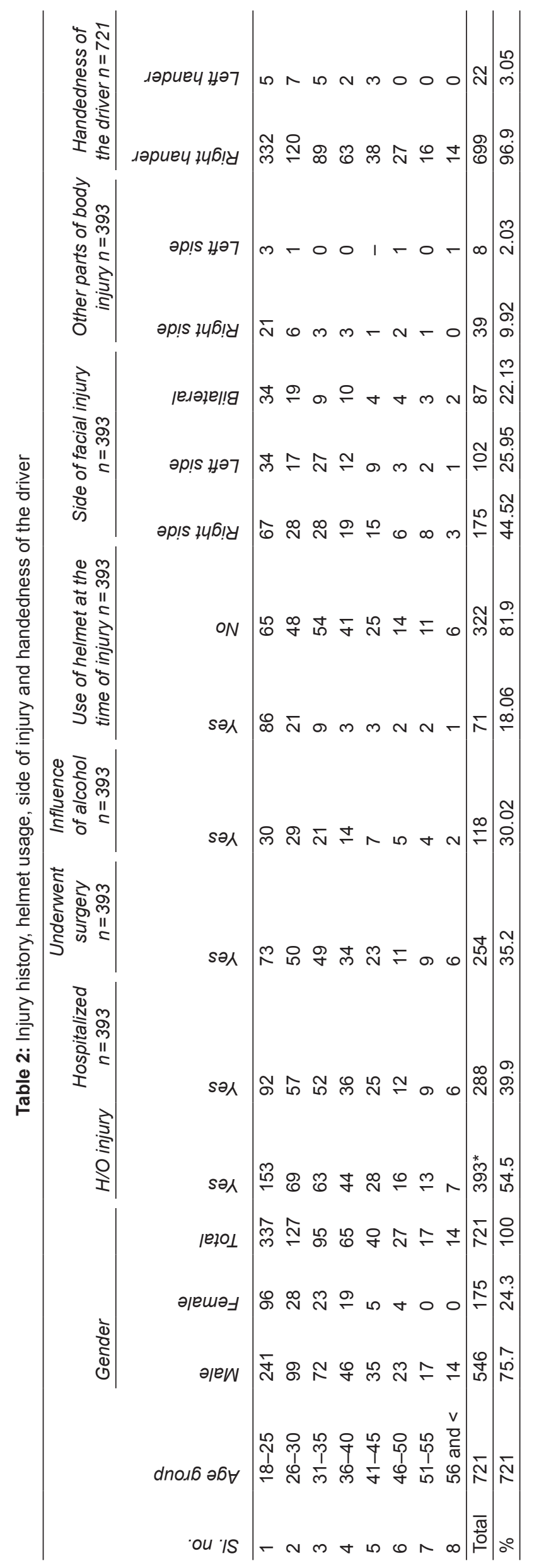




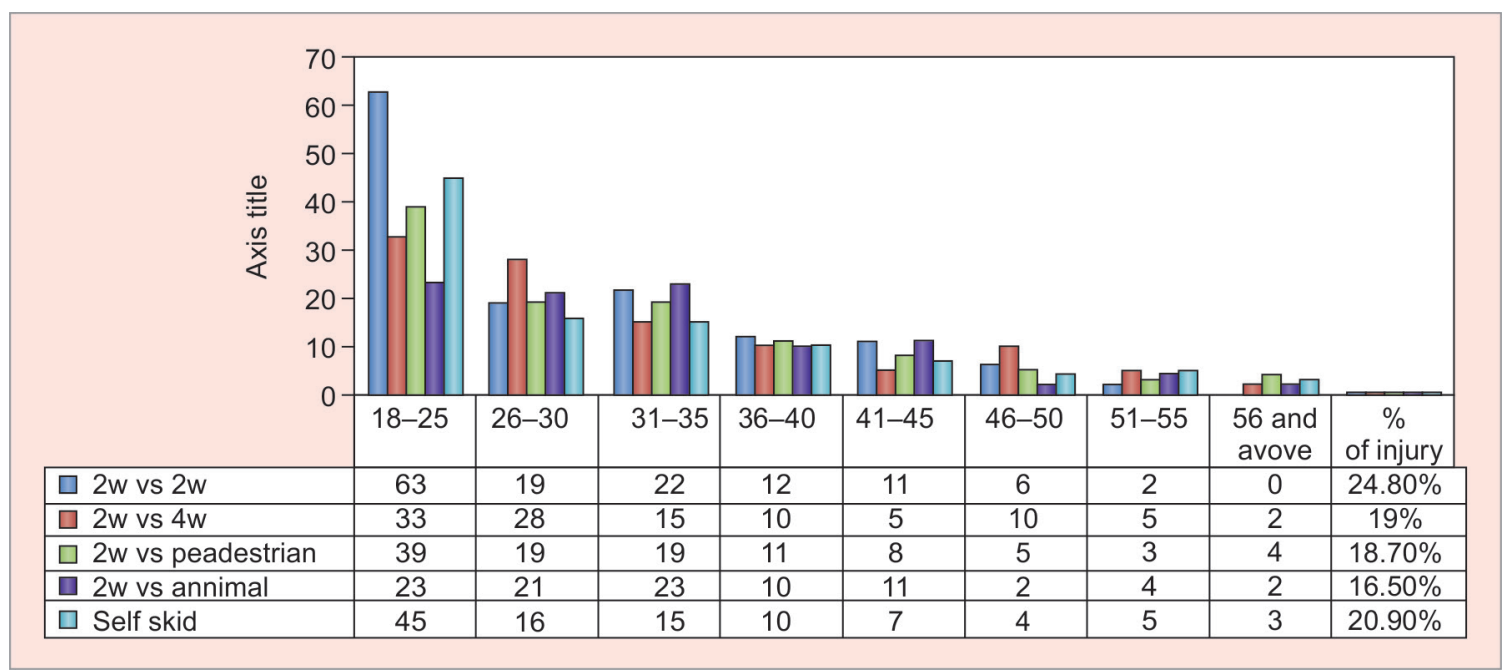

Graph 2: Mode of injury in road traffic accidents by MTWs

times. Out of 393 injured persons, 39.9\% had been admitted in hospital and $35.2 \%$ of them underwent minor to major surgery for facial injuries, including treatment for facial bone fractures. Only $39.4 \%$ of females had accidents when compared with $59.3 \%$ of males who had accidents. The difference is statistically significant $(p<0.0001)$.

\section{Mode of Injury}

Graph 2 was established based on the previously reported histories:

Category I: Two wheeler vs two wheeler accounts for nearly $24.8 \%$;

Category II: Two wheeler vs four wheeler like car/lorry/ truck/van etc. accounts nearly 19\%;

Category III: Two wheeler met the accident because of sudden pedestrians crossing which was about $18.7 \%$;

Category IV: Injury due to two wheeler vs animal crossing was $16.5 \%$;

Category $V$ : Injury due to skid/fall from two wheeler by sudden loss of control over vehicle due to other reasons/ lost control because of influence of alcohol was reported as $20.9 \%$.

\section{Influence of Alcohol}

Nearly $30.02 \%$ were reported that they had under the influence of alcohol at the time of the accident.

\section{Side of Injury on the Face}

Graph 3 shows $44.52 \%$ had an injury on the right side of the face; $25.95 \%$ had left-side injury; $22.13 \%$ had the bilateral injury. Again right-side injuries are more $(44.5 \%)$ as compared with the left side (25.9\%). The difference is statistically significant $(\mathrm{p}<0.0001)$. Injury on the right side of the body was about $9.92 \%$, and left side body was $2.03 \%$.

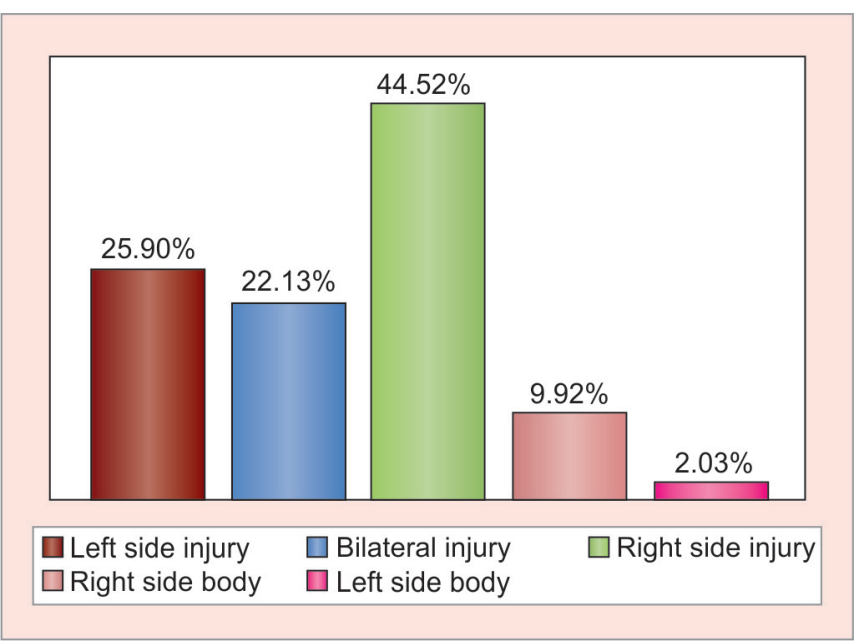

Graph 3: Side of injury in road traffic accidents by MTWs

\section{Handedness of the Driver}

Out of 721 participants, $96.9 \%$ were right-handers and $3.05 \%$ were left-handers.

\section{DISCUSSION}

These findings are obvious important implications for the clinical evaluation and the future design of injury prevention strategies for the MTW drivers. In our study population, the male/female participants proportion was 3.1:1; in Chakranarayan et $\mathrm{al},{ }^{9}$ Salonen et $\mathrm{al}^{10}$ have reported that male vehicle drivers are far outnumbered than females, explained by the fact that men are more involved in outdoor activities and are also exposed to maxillofacial injuries; as compared with females; the incidence of maxillofacial fractures was high in male than in female in the ratio of 4.2:1.

In the age group from 18 to 50 years, bike users are more than scooter and mopeds. Once the age increases, the scooter/moped usage are equal to or slightly more 
than bike users. This shows that the young adults, especially males, prefer bikes - particularly geared vehicle between 100 and $220 \mathrm{cc}$, because of the speed, convenience, and their passion in using these types of vehicles. In this study, only $2 \%$ of them are using above $300 \mathrm{cc}$; this could be explained by the fact that higher cc vehicles are expensive, maybe not preferred or afford to buy. In our study, most of the females are using vehicles without gear and less than $80 \mathrm{cc}$ engine capacity vehicles because of the light-weight models and their convenient.

The average speed of the female riders is less $40 \mathrm{~km} /$ hour and maximum $60 \mathrm{~km} /$ hour. $62 \%$ of males (between 18 and 35 years) had reported that their average speed would be between 80 and $100 \mathrm{~km} /$ hour and $30 \%$ above $100 \mathrm{~km} /$ hour. As age (40 and above) increases the average speed are less than $50 \mathrm{~km} /$ hour. In the city like Chennai because of the congested traffics, particularly in the working hours, this could be the possible speed. Other studies reported that during night hours, weekend holidays, the incidence are more because of the over speed, less traffic in the roads, the holiday mood of youngsters, and consuming alcohols in weekends, all may precipitate the etiology for a number of accidents. Our study also supports their findings.

In our study, young adults reported that they are mostly using the helmet when compared with an age group of 45 and above. This shows some positive sign of awareness about usage of the helmet in the young minds regarding injury prevention efforts. $81 \%$ of participants were not wearing helmets at the time of injury, though they are regular users of helmets. $11 \%$ participants had the injury on other parts of the body, and reported that because of the usages of helmet they did not get injury in the face/head. Using helmets reduce the possibility of the incidence of head injury victims. Lee et $\mathrm{al}^{11,12}$ reported that because of hot weather in Thailand using helmet becomes discomfort for the bike riders, so in Chennai also that could be one of the reasons for not able to use the helmet regularly. Subhashraj et $\mathrm{al}^{13}$ reported that motorbike accidents are frequent in India due to socioeconomic conditions, speeding, and not wearing a helmet or safety equipment.

Bali et $\mathrm{al}^{14}$ reported that road traffic accidents being $71.9 \%$ are commonly in the 20 to 40 age group; most of them were driving two wheelers and mostly under the effect of alcohol. A total of $66.2 \%$ were on two wheelers, among whom $10 \%$ were wearing the helmet. Laverick et $\mathrm{al}_{,}^{15}$ Maaytah et $\mathrm{al}_{1}^{16}$ and Septa et $\mathrm{al}^{17}$ reported that there is a definite association of influence of alcohol with maxillofacial injuries. Brasileiro and Passeri, ${ }^{18} \mathrm{Al}$ Ahmed et $\mathrm{a}^{19}$ reported that men aged 21 to 40 years represent a group with intense social interaction and higher rates of morbidity, susceptible to road traffic accidents. Our study reports that nearly $30 \%$ males were under the influence of alcohol at the time of injury, which could be one of the causes of injury. Victims may not be in a position to take a decision in an unexpected situation and lost their control over the vehicle.

The majority (24.8\%) of injuries were due to two wheeler vs two-wheeler accidents, $20.9 \%$ of injuries are due to selffall/skid, $19 \%$ of injuries by two wheelers met accidents with four wheelers and had poly trauma, $18.7 \%$ of accidents by pedestrians crossing, and $16.7 \%$ by animal crossing. Samieirad et $\mathrm{al}^{20}$ reported that left injuries were common next to bilateral injuries. Das et al ${ }_{1}^{8}$ Chakranarayan et $\mathrm{al}^{9}$ reported right-side injuries were common than left side injuries but have not mentioned about the reasons for common occurrence on a particular side. In our study, right-side injuries were more than the left side. Injury mainly by four wheeler impacts were bilateral and multiple injuries. They reported that because of a sudden cross of animal/pedestrian cross/ speed breaker, they applied break for front wheel by righthand side, then they lost the control of the vehicle and fall from the bike. A total of $96.3 \%$ of our participants are righthanders, which could be one of the reasons for right-side injuries by skid and fall from two wheeler, though other studies have mentioned about the frequently involving side of injuries in their retrospective studies. They have not analyzed any factors for the side of injuries.

Further study needs to confirm these findings to take decision-making policies, regarding vehicle modifications to prevent injury from MTWs. Most of the populations are right-handers only. Though the left-handers are very few, they were also to be considered while making vehicle modifications. Break systems and stability of MTWs to be improved. Usage of helmets should be made mandatory, enforcement of the law for drink and drive should be strict to prevent injury and related morbidity and mortality.

\section{CONCLUSION}

Motorized two wheelers are one of the main and essential transports for working, the middle, and low-income group in developing countries like India. It is our duty to improve the safety for the road riders, pedestrians, and pillion riders by improving the quality and safe road transportation system for these vulnerable groups of road users.

\section{REFERENCES}

1. Bansal A, Liu Z, Menon B, Mokashi A, Ranganathan N. Urban transport. India's transport sector: the challenges ahead. Washington (DC): World Bank; 2002. p. 78-90.

2. Malta DC, Mascarenhas MDM, Bernal R, da Silva Junior JB. Accidents by external causes in adolescents: care in sentinel urgency and emergency services in the Brazilian State Capitals - 2009. Ciencia Saude Coletiva 2012 Sep;17(9):2291-2304. 
3. Rajput D, Bariar LM. Study of maxillofacial trauma, its aetiology, distribution, spectrum, and management. J Indian Med Assoc 2013 Jan;111(1):18-20.

4. Mishra BK, Banerji AK, Mohan D. Two-wheeler injuries in Delhi, India: a study of crash victims hospitalized in a neurosurgery ward. Accid Anal Prev 1984;16(5-6):407-416.

5. Mohan D, Bawa PS. Analysis of road traffic fatalities in Delhi, India. Accid Anal Prev 1985;17(1):33-45.

6. Mohan D, Kothiyal KP, Misra BK, Banerji AK. Helmet and head injury study of crash involved motorcyclists in Delhi. In: Proceedings 1984 International Conference on the Biomechanics of Impacts. Bron, France: IRCOBI; 1984. p. 65-77.

7. Mohan D. Transportation Research and Injury Prevention Programme (TRIPP). Bulletin 2006;3(3):1-2.

8. Das AK, Bandopadhyay M, Chattopadhyay A, Biswas S, Saha A, Balkrishna UM, Nair V. Clinical evaluation of neurosensory changes in the infraorbital nerve following surgical management of zygomatico-maxillary complex fractures. J Clin Diagn Res 2015 Dec;9(12):ZC54-ZC58.

9. Chakranarayan A, Thapliyal GK, Sinha R, Suresh MP. Efficacy of two point rigid internal fixation in the management of zygomatic complex fracture. J Maxillofac Oral Surg 2009 Sep;8(3):265-269.

10. Salonen EM, Koivikko MP, Koskinen SK. Violence-related facial trauma: analysis of multidetector computed tomography findings of 727 patients. Dentomaxillofac Radiol 2010 Feb;39(2):107-112.

11. Lee KH, Steenberg LJ. Equine-related facial fractures. Int J Oral Maxillofac Surg 2008 Nov;37(11):999-1002.
12. Lee MC, Chiu WT, Chang LT, Liu SC, Lin SH. Craniofacial injuries in unhelmeted riders of motorbikes. Injury 1995 Sep;26(7):467-470.

13. Subhashraj K, Ramkumar S, Ravindran C. Pattern of mandibular fractures in Chennai, India. Br J Oral Maxillofac Surg 2008 Mar;46(2):126-127.

14. Bali R, Sharma P, Garg A, Dhillon G. A comprehensive study on maxillofacial trauma conducted in Yamunanagar, India. J Inj Violence Res 2013 Jun;5(2):108-116.

15. Laverick S, Patel N, Jones DC. Maxillofacial trauma and the role of alcohol. Br J Oral Maxillofac Surg 2008 Oct;46(7): 542-546.

16. Maaytah M, Smith SF, Jerjes W, Upile T. The effect of the new "24 hour alcohol licensing law" on the incidence of facial trauma in London. Br J Oral Maxillofac Surg 2008 Sep;46(6): 460-463.

17. Septa D, Newaskar VP, Agrawal D, Tibra S. Etiology, incidence and patterns of mid-face fractures and associated ocular injuries. J Maxillofac Oral Surg 2014 Jun;13(2):115-119.

18. Brasileiro BF, Passeri LA. Epidemiological analysis of maxillofacial fractures in Brazil: a 5-year prospective study. Oral Surg Oral Med Oral Pathol Oral Radiol Endod 2006 Jul;102(1):28-34.

19. Al Ahmed HE, Jaber MA, Abu Fanas SH, Karas M. The pattern of maxillofacial fractures in Sharjah, United Arab Emirates: a review of 230 cases. Oral Surg Oral Med Oral Pathol Oral Radiol Endod 2004 Aug;98(2):166-170.

20. Samieirad S, Tohidi E, Shahidi-Payam A, Hashemipour MA, Abedini A. Retrospective study maxillofacial fractures epidemiology and treatment plans in Southeast of Iran. Med Oral Patol Oral Cir Bucal 2015 Nov 1;20(6):e729-e736. 